\title{
Mir-208 promotes cell proliferation by repressing SOX6 expression in human esophageal squamous cell carcinoma
}

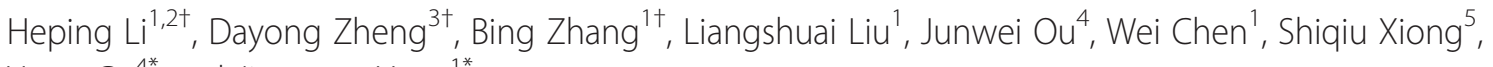
Yong $\mathrm{Gu}^{4^{*}}$ and Jianyong Yang ${ }^{1 *}$

\begin{abstract}
Background: Esophageal squamous cell carcinoma (ESCC) is the major histological type of esophageal cancer in developing countries. The prognosis and survival rate of ESCC are very poor. Recently, microRNAs (miRNAs) have emerged as important regulators of cancer cell biological processes. To better understanding the molecular mechanisms by which they regulate the behavior of cancer cells is needed.

Methods: The expression of miR-208 was examined in ESCC cell lines and tumor tissues by real-time PCR. Proliferation capability of ESCC cells upon regulation of miR-208 expression was detected by MTT assay, colony formation assay, anchorage-independent growth ability assay and flow cytometry analysis. The target of miR-208 was determined by western blotting analysis, luciferase reporter assay and real-time PCR.

Results: miR-208 was upregulated in ESCC cell lines and tissues. Overexpression of miR-208 in ESCC cells increased cell proliferation, tumorigenicity and cell cycle progression, whereas inhibition of miR-208 reduced cells proliferation, tumorigenicity and cell cycle progression. Additionally, SOX6 was identified as a direct target of miR-208. Ectopic expression of miR-208 led to downregulation of SOX6 protein, which resulted in the downregulation of p21, upregulation of cyclin D1 and phosphorylation of Rb.
\end{abstract}

Conclusions: These results suggest that miR-208 represents a potential onco-miR and participates in ESCC carcinogenesis by suppressing SOX6 expression.

Keywords: miR-208, SOX6, Esophageal squamous cell carcinoma, Proliferation

\section{Introduction}

Esophageal cancer, one of the most common malignant tumors, is the eighth most common cancer and the sixth most common causes of cancer mortality in the world [1]. According to its pathological characteristics, it has two main subtypes, ESCC and esophageal adenocarcinoma (EAC) [1,2]. ESCC is the major histological type of esophageal cancer in developing countries [3]. Although advances have been made in the treatment of ESCC, including surgery, chemotherapy, radiation or a combination of these

\footnotetext{
* Correspondence: ygzihu@163.com; Jianyongyang0899@hotmail.com ${ }^{\dagger}$ Equal contributors

${ }^{4}$ Department of Thoracic Surgery, the First Affiliated Hospital of Sun Yat-sen University, Guangzhou 510080, P.R. China

${ }^{1}$ Department of Medical Imaging, the First Affiliated Hospital of Sun Yat-sen University, Guangzhou 510080, P.R. China

Full list of author information is available at the end of the article
}

options, the prognosis of ESCC patients remains very poor, which the overall 5-year survival rate of patient after surgery is only about $14-22 \%[3,4]$. Some oncogenic and tumor suppressive factors have been reported to be associated with ESCC progression; however, few of them were specific and conclusive $[5,6]$. Further information on the biological behavior involved in esophageal cancer initiation and progression, especially in ESCC, is important for the development of effective diagnostic methods and therapeutic strategies.

MiRNAs, a class of small non-coding RNAs of 20-22 nucleotides, are involved in multiple biological processes, such as cell differentiation, proliferation, oncogenesis, angiogenesis and cell invasion [7-9]. MiRNAs play essential roles during human cancer progression by targeting the 3 ' untranslated region ( $3^{\prime}$-UTR) of mRNAs in a sequence-specific 
manner for translational repression or degradation [10,11]. In view of the close relationship between miRNAs and the biological progression of multiple cancers, miRNAs are presently considered as potential novel targets for anticancer therapies [9-12].

SOX6, a member of the D sub family of the sex determining region Y (SRY)-box-related transcription factors, contains a conserved high-mobility-group (HMG) DNA-binding domain and plays important roles in biological progression $[13,14]$. SOX6 has been reported to play a tumor-suppressive function in certain tumors. It is frequently downregulated and significantly associated with better prognosis in primary ESCC and hepatocellular carcinoma $[15,16]$.

In this study, we found that miR-208 is upregulated in ESCC cell lines and tissues. We verified a functional role for miR-208 in ESCC cell proliferation, tumorigenicity and cell cycle regulation. Furthermore, our data indicated that SOX6 mRNA is a target of miR-208 and that SOX6 is essential for the regulation of miR-208 in ESCC cells in vitro. Our results suggest that miR-208 may promote cell proliferation, tumorigenicity and cell cycle progression in ESCC through the SOX6-mediated signaling pathway.

\section{Material and methods \\ Cell culture}

Primary culture of normal esophageal epithelial cells (NEEC) was established from fresh specimens of the adjacent noncancerous esophageal tissue, which is over $5 \mathrm{~cm}$ from the cancerous tissue, according to a previous report [17]. The ESCC cell lines, including Kyse140, Kyse30, Kyse510, Kyse520, Eca109, TE-1, Kyse410, Kyse180, EC18, HKESC1 and 108CA, were grown in the Dulbecco's modified Eagle's medium (DMEM, Invitrogen, Carlsbad, CA, USA) supplemented with $10 \%$ fetal bovine serum (FBS) (HyClone, Logan, UT, USA), 100 units of penicillin and 100 units of streptomycin at $37^{\circ} \mathrm{C}$ in a $5 \% \mathrm{CO}_{2}$ atmosphere in a humidified incubator.

\section{Tissue specimens}

For the use of the clinical materials for research purposes, prior patient consent and approval from the Institutional Research Ethics Committee were obtained. This study was conducted on 10 pairs of snap-frozen ESCC tumor and matched normal tissues from adjacent regions, which were histopathologically diagnosed at the First Affiliated Hospital of Sun Yat-sen University from 2001 to 2006. The 10 ESCC tissues and the matched adjacent noncancerous esophageal tissues were frozen and stored in liquid nitrogen until further use.

\section{Generation of stably engineered cell lines}

The miR-208 expression plasmid was generated by cloning the genomic pre-miR-208 gene, with 300-bp on each flanking side, into retroviral transfer plasmid pMSCV-puro
(Clontech Laboratories Inc., Moutain View, CA, USA) to generate plasmid pMSCV-miR-208. The non-targeting control microRNA (negative control mimic), which are designed computationally to have no perfect seed-sequence matches to the transcriptome, was subcloned into retroviral transfer plasmid pMSCV to generate the plasmid pMSCVNC. pMSCV-miR-208 or pMSCV-NC was cotransfected with the PIK packaging plasmid into 293FT cells using the standard calcium phosphate transfection method [18]. Thirty-six hours after cotransfection, supernatants were collected and incubated with cells to be infected for 24 hours in the presence of polybrene $(2.5 \mu \mathrm{g} / \mathrm{ml})$. After infection, puromycin $(1.5 \mu \mathrm{g} / \mathrm{ml})$ was used to select stably transduced cells over a 10-day period.

RNA extraction, reverse transcription (RT) and real-time PCR Total cellular RNA was extracted using the Trizol reagent (Invitrogen, Carlsbad, CA, USA) according to the manufacturer's instruction. cDNAs were amplified and quantified in an ABI Prism 7500 Sequence Detection System (Applied Biosystems, Foster City, CA, USA) using dye SYBR Green I (Molecular Probes, Invitrogen). The primers selected were as follows:

\section{p21 forward: 5'-CATGGGTTCTGACGGACAT -3', p21 reverse: 5' - AGTCAGTTCCTTGTGGAGCC -3'; Cyclin D1 forward: 5'-AACTACCTGGACCGCTTCCT -3', Cyclin D1 reverse: 5'-CCACTT GAGCTTGTTCACCA-3'.}

Expression levels of genes were normalized to that of the housekeeping gene GAPDH as the control (GAPDH forward primer, 5'-GACTCATGACCACAGTCCA TGC-3'; reverse primer, 3'-AGAGGCAGGGATGATGTTCTG-5'), and calculated as $2^{-[(\mathrm{Ct} \text { of } \mathrm{p} 21, \mathrm{CyclinD} 1)-(\mathrm{Ct} \text { of } G A P D H)]}$, where $\mathrm{C}_{t}$ represents the threshold cycle for each transcript. The expression of the miRNA was defined based on the threshold cycle $(\mathrm{Ct})$, and relative expression levels were calculated as $2^{-[(\mathrm{Ct} \text { of miR-208) - (Ct of U6)] }}$ after normalization with reference to expression of U6 small nuclear RNA.

\section{Western blotting}

Western blotting analysis was performed according to standard methods, as previously described [19]. The membranes were probed with polyclonal rabbit antibodies against anti-SOX6 (1:500; Abcam, Cambridge, MA, USA), anti-p21, anti-cyclinD1 and anti-Rb, anti-phosphorylated Rb (1:1,000; Cell Signaling, Danvers, MA, USA). The membranes were stripped and re-probed with an anti- $\alpha$-Tubulin mouse monoclonal antibody (1:1,000; Sigma, Saint Louis, $\mathrm{MO}, \mathrm{USA})$ as a loading control.

\section{Plasmid, oligonucleotides, siRNA and transfection}

The region of the human SOX6 3'-UTR, from 1 to $1100 \mathrm{bp}$, generated by PCR amplification from DNA of 
the Eca109 cells, was cloned into vector pGL3 (Promega, Madison, WI, USA). The primers selected were as follows: SOX6-3'UTR-wt-up: 5' - GCCCCGCGGTGGCTCCACA ATTACATCAGC -3', SOX6-3'UTR-wt-dn: 3' - GCCCT GCAGCATAAAATCACTATGTACACAGGA -5'. The miR-208 mimic, miR-208 inhibitor and negative control (NC) were purchased from RiboBio (RiboBio Co. Ltd, Guangzhou, Guangdong, China). For depletion of SOX6, the siRNA was synthesized and purified by RiboBio. The SOX6 siRNA sequences used were: CGGGAAACTGTCC TCCATAAA. Transfection of oligonucleotides and siRNA were performed using the Lipofectamine 2000 reagent (Invitrogen, Carlsbad, CA) according to the manufacturer's instruction.

\section{Luciferase assay}

ESCC cells $\left(3.5 \times 10^{4}\right)$ were seeded in triplicate in 24-well plates and allowed to settle for $12 \mathrm{~h}$. One hundred nanograms of pGL3-SOX6-luciferase plasmid was transfected into ESCC cells using the Lipofectamine 2000 reagent (Invitrogen). Medium was replaced after $6 \mathrm{~h}$, and luciferase and renilla signals were measured $48 \mathrm{~h}$ after transfection using the Dual Luciferase Reporter Assay Kit (Promega) according to the manufacturer's protocol. Three independent experiments were performed and the data were presented as the mean \pm SD.

\section{3-(4, 5-Dimethyl-2-thiazolyl)-2, 5-diphenyl-2H-tetrazolium bromide (MTT) assay}

Kyse30 and Kyse410 cells, seeded on 96-well plates, were stained at the indicated time points with $100 \mu \mathrm{l}$ sterile MTT dye $\left(0.5 \mathrm{mg} / \mathrm{ml}\right.$, Sigma) for $4 \mathrm{~h}$ at $37^{\circ} \mathrm{C}$, followed by removal of the culture medium and addition of $150 \mu \mathrm{l}$ dimethyl sulfoxide (Sigma). The absorbance was measured at $570 \mathrm{~nm}$, with $655 \mathrm{~nm}$ as the reference wavelength. All experiments were performed in triplicate.

\section{Colony formation assay}

Cells were plated on a 6 -well plate $\left(0.5 \times 10^{3}\right.$ cells per well) and cultured for 10 days. The colonies were stained with $1.0 \%$ crystal violet for $1 \mathrm{~min}$ after fixation with $10 \%$ formaldehyde for $5 \mathrm{~min}$. The experiment was performed independently three times for each cell line.

\section{Anchorage-independent growth ability assay}

One thousand cells were trypsinized and suspended in $2 \mathrm{ml}$ complete medium plus $0.33 \%$ agar (Sigma). The agar-cell mixture was plated on top of a bottom layer comprising $0.66 \%$ complete medium agar mixture. After 10 days, colony sizes were measured with an ocular micrometer and colonies greater than $0.1 \mathrm{~mm}$ in diameter were counted. The experiment was performed for independently three times for each cell line.

\section{Flow cytometry analysis}

All cells in a culture dish were harvested by trypsinization, washed in ice-cold PBS, and fixed in $80 \%$ ice-cold ethanol. Before staining, the cells were pelleted in a cooled centrifuge and resuspended in cold PBS. Bovine pancreatic RNAase (Sigma) was added at a final concentration of $2 \mu \mathrm{g} / \mathrm{ml}$, and cells were incubated at $37^{\circ} \mathrm{C}$ for $30 \mathrm{~min}$, followed by incubation in $20 \mu \mathrm{g} / \mathrm{ml}$ propidium iodide (Sigma) for $20 \mathrm{~min}$ at room temperature. 20,000 cells were analyzed on a flow cytometer (FACSCalibur; BD Biosciences, Bedford, MA, USA).

\section{Statistical analysis}

Student's $t$ test was used to evaluate the significant difference of two groups of data in all the pertinent experiments. A $P$ value $<0.05$ (using a two-tailed paired $t$ test) was considered significantly different for two groups of data.

\section{Results}

miR-208 expression is elevated in ESCC cell lines and tissues

Real-time PCR analysis revealed that miR-208 expression was markedly increased in all eleven ESCC cell lines, including Kyse140, Kyse30, Kyse510, Kyse520, Eca109, TE-1, Kyse410, Kyse180, EC18, HKESC1 and 108CA, compared with that in NEEC (Figure 1A). Moreover, comparative analysis revealed that miR-208 was significantly overexpressed in 10 pairs of cancerous tissues compared with the adjacent noncancerous esophageal tissues (Figure 1B). Collectively, these results suggested that miR-208 was upregulated in ESCC.

\section{Ectopic expression of miR-208 enhances proliferation of ESCC cells}

To investigate the effect of miR-208 on the development and progression of ESCC, Kyse30 and Kyse410 ESCC cells, which were with medium-level of miR-208 expression, stably overexpressing miR-208 were established (Figure 2A). The MTT and colony formation assays showed that overexpression of miR-208 dramatically increased the growth rate of both ESCC cell lines compared with that of control cells (Figure 2B and C). Importantly, the anchorageindependent growth assay revealed that both Kyse30miR-208 and Kyse410-miR-208 cells showed more and larger-sized colonies than their corresponding control cells (Figure 2D). Moreover, we analyzed the cell cycle of Kyse30-miR-208 and Kyse410-miR-208 cells by flow cytometry, which showed a significant decrease in the percentage of cells in G1/G0 phase and an increase in the percentage of cells in $S$ phase (Figure 2E). All these results suggested that upregulation of miR-208 promoted the proliferation and tumorigenicity of ESCC cells. 

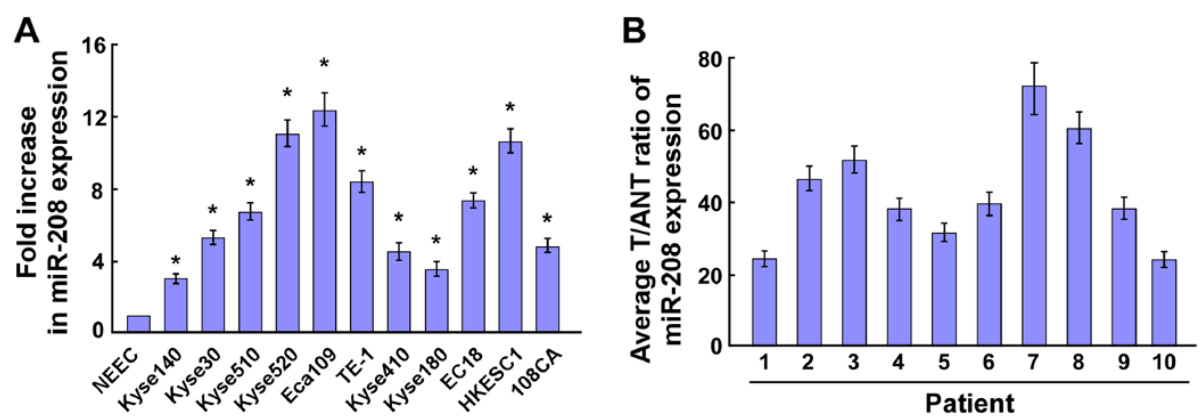

Figure 1 Expression of miR-208 is increased in ESCC cell lines and tissues. A. Real-time PCR analysis of miR-208 expression in normal esophageal epithelial cells (NEEC) and esophageal squamous carcinoma cells, including Kyse140, Kyse30, Kyse510, Kyse520, Eca109, TE-1, Kyse410, Kyse180, EC18, HKESC1 and 108CA. Transcript levels were normalized using U6 expression. B. The expression of miR-208 was examined in 10 paired cancerous tissues (T) and their adjacent noncancerous esophageal tissues (ANT). The average miR-208 expression was normalized using U6 expression. Each bar represents the mean $\pm \mathrm{SD}$ of three independent experiments. ${ }^{*} P<0.05$.

Inhibition of miR-208 reduces proliferation of ESCC cells To further test whether endogenous miR-208 helps to sustain the proliferative property of ESCC cells, loss-offunction studies using a miR-208 inhibitor were used to further investigate whether endogenous miR-208 helps to maintain the proliferative properties of ESCC cells. As shown in Figure 3A, B and C, suppression of miR-208 by transfection with the miR-208 inhibitor significantly decreased the growth rate of both ESCC cell lines as compared with that of NC transfected cells. The anchorageindependent growth assay revealed that both Kyse30-miR208-inhibitor and Kyse410-miR-208-inhibitor cells formed fewer and smaller-sized colonies than their corresponding negative control cells, indicating the inhibitory function of miR-208 inhibitor on ESCC tumorigenicity (Figure 3D). Additionally, flow cytometry showed a significant increase in the percentage of cells in G1/G0 phase and a decrease in the percentage of cells in S phase in Kyse30-miR-208inhibitor and Kyse410-miR-208-inhibitor cells compared with NC transfected cells (Figure 3E). These results suggested that downregulation of miR-208 could suppress the proliferation and tumorigenicity of ESCC cells.

\section{SOX6 is a direct target of miR-208 in ESCC cells}

A previous study showed that SOX6 is a tumor-suppressor and plays an important role in ESCC progression [1]. Using publicly available algorithms (TargetScan, Pictar, miRANDA), we found that SOX6 was a potential target of miR-208 (Figure 4A). As predicted, western blotting analysis revealed that SOX6 expression decreased in the Kyse30 and Kyse410 ESCC cells ectopic expressing miR-208 and increased in cells suppressing miR-208 (Figure 4B). To examine whether miR-208 mediatedSOX6 downregulation was through the 3'-UTR of SOX6, the SOX6- 3'-UTR fragment, containing three miR-208 binding sites, was subcloned into a pGL3 luciferase reporter vector. The results of the luciferase reporter assay showed that overexpression of miR-208 decreased, and suppression of miR-208 increased, the luciferase activity of the SOX6 3'-UTR-luciferase reporter, whereas a miR-208 with mutated seed sequence failed to show an inhibitory effect on the luciferase activity (Figure 4C). Meanwhile, we observed that the mRNA of the SOX6 downstream gene, $p 21$ was significantly downregulated, and that of Cyclin D1 was significantly upregulated, by miR-208 (Figure 4D). Moreover, the expression level of the p21 protein was downregulated, Cyclin D1 was upregulated, and phosphorylated Rb was increased in miR-208 overexpressing cells compared with the negative control cells. In contrast, the expression level of p21 was upregulated, Cyclin D1 was downregulated, and Rb phosphorylation was decreased in cells transfected with the miR-208 inhibitor (Figure 4E). Collectively, our results suggested that SOX6 was a bona fide target of miR-208.

\section{SOX6 suppression is critical for miR-208-induced cell proliferation in ESCC}

To investigate the effect of SOX6 reduction on ESCC progression, we repressed endogenous SOX6 expression using a SOX6-specific siRNA (Figure 5A). The MTT assay and the colony formation assay both showed that silencing SOX6 in miR-208 inhibitor transfected cells increased the growth rate of the cells (Figure $5 \mathrm{~B}$ and $\mathrm{C}$ ). The anchorageindependent growth assay showed similar results (Figure 5D). All the results suggested that further silencing SOX6 expression in Kyse30-miR-208-inhibitor and Kyse410-miR208-inhibitor cells could reverse the inhibitory effect of the miR-208 inhibitor on ESCC cells proliferation. These data confirmed that miR-208 promoted ESCC cells proliferation and tumorigenicity by repressing endogenous SOX6 expression and that SOX6 plays important role in miR-208-mediated cell proliferation.

\section{Discussion}

In the current study, we demonstrated that miR-208 is upregulated in ESCC cell lines and tissues. Overexpression 


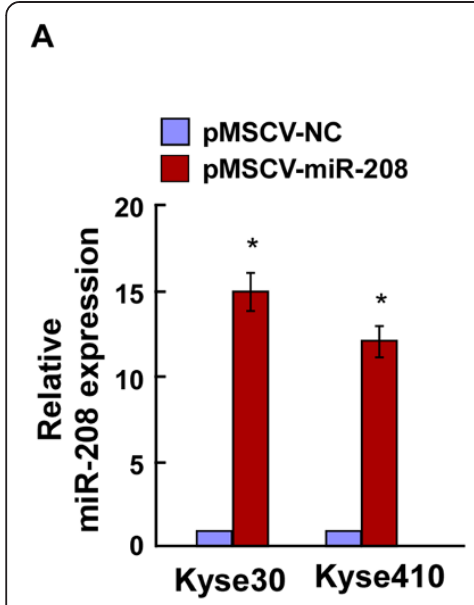

C

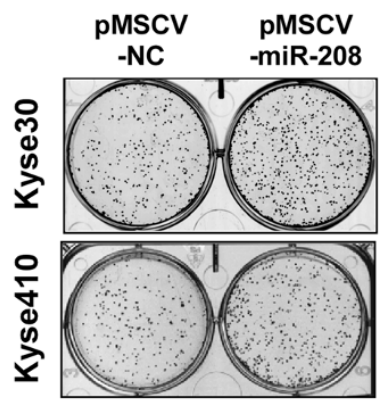

E

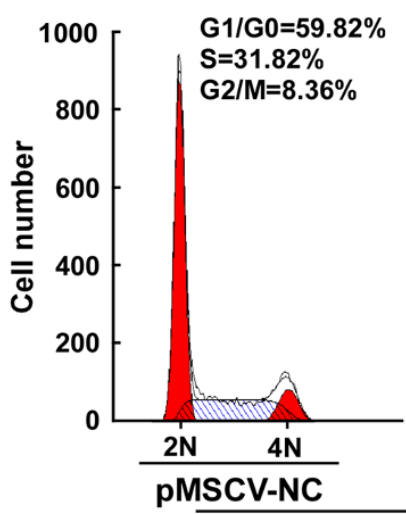

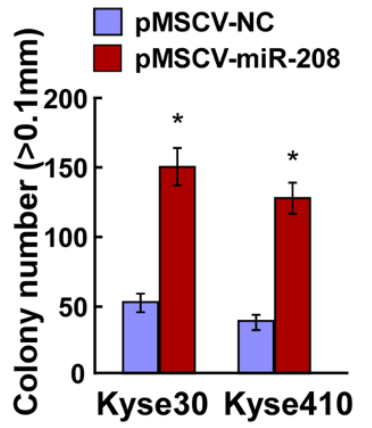
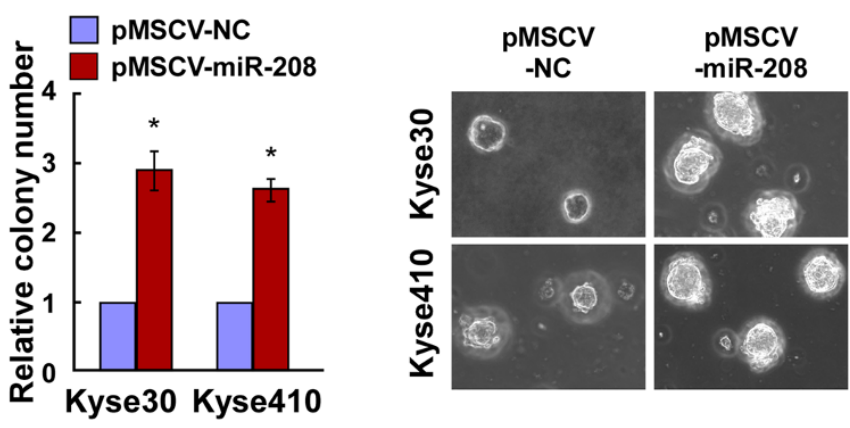

B

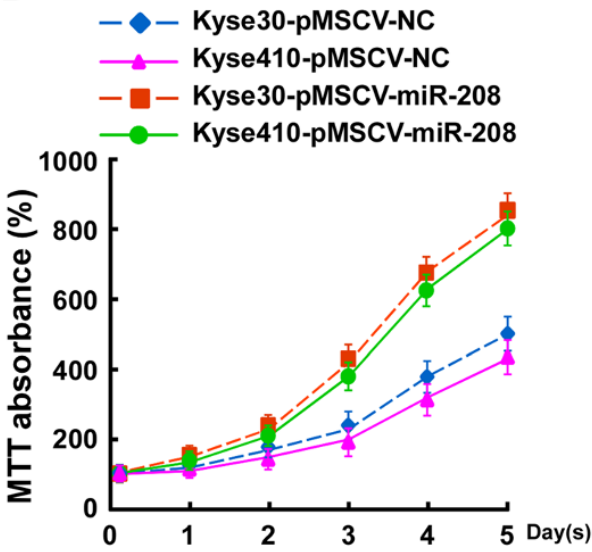

D

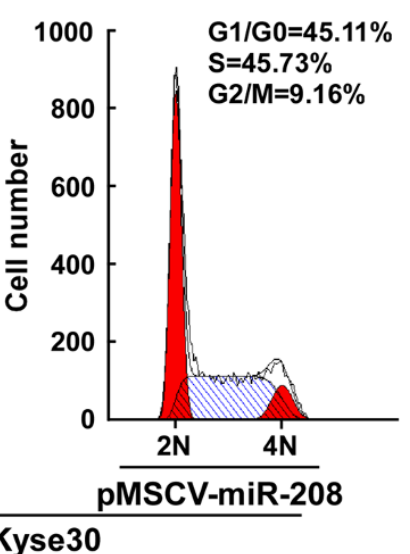

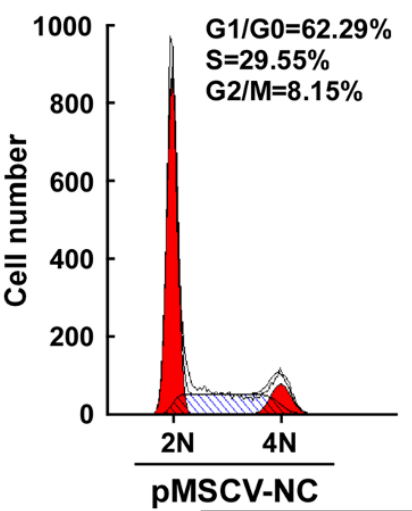

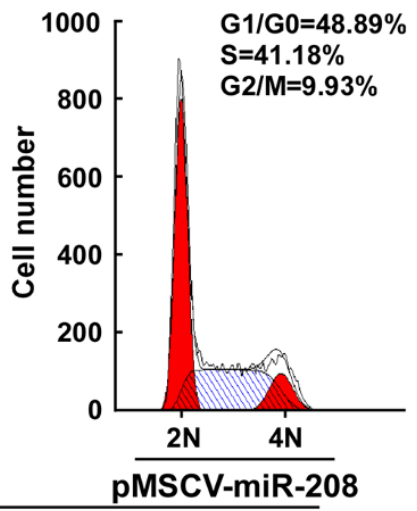

Kyse410

Figure 2 Upregulation of miR-208 promotes the proliferation ability of ESCC cells. A. Real-time PCR analysis of miR-208 expression in Kyse30 and Kyse410 cells stably expressing miR-208 and in control cells. B. Effects of ectopic miR-208 on the proliferation of Kyse30 and Kyse410 cells lines analyzed by the MTT assay. C. Representative micrographs (left) and quantification (right) of crystal violet stained cell colonies formed by the indicated ESCC cell lines, 10 days after inoculation. D. Effects of ectopic miR-208 on the tumorigenicity of Kyse30 and Kyse410 cell lines, as determined by an anchorage-independent growth ability assay. Colonies larger than $0.1 \mathrm{~mm}$ were scored. E. Effects of miR-208 overexpression on the cell cycle progression of ESCC cells measured by flow cytometry analysis. Each bar represents the mean \pm SD of three independent experiments. ${ }^{*} P<0.05$.

of miR-208 promotes the proliferation and tumorigenicity of ESCC cells, probably through post-translationally downregulating SOX6 expression by targeting its mRNA
3'- UTR. The negative regulation of SOX6 by miR-208 leads to upregulation of $\mathrm{p} 21$, downregulation of cyclinD1, and $\mathrm{Rb}$ phosphorylation. We demonstrated that miR-208 


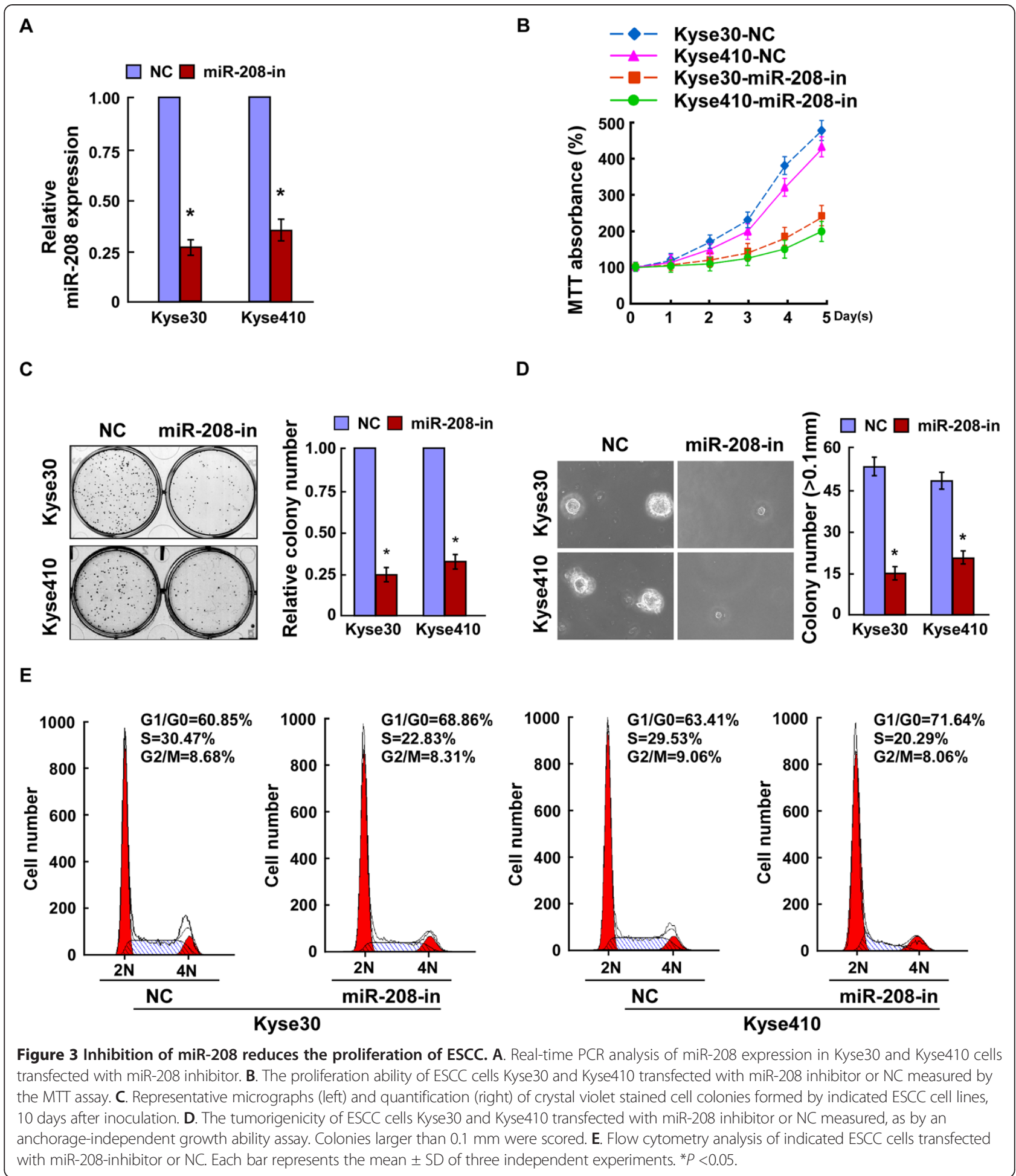

might play essential role via the SOX6-mediated pathway during ESCC progression.

Recent studies showed that miRNAs regulated various cellular pathways by affecting the expression of multiple target genes $[8,20]$. The expression of miRNAs might contribute to human carcinogenesis and cancer progression, and are considered as potential novel targets for cancer diagnosis and therapy [21-24]. miR-208 has been identified as a myomiR. It is specifically expressed at much higher levels in cardiac tissue and is dysregulated 


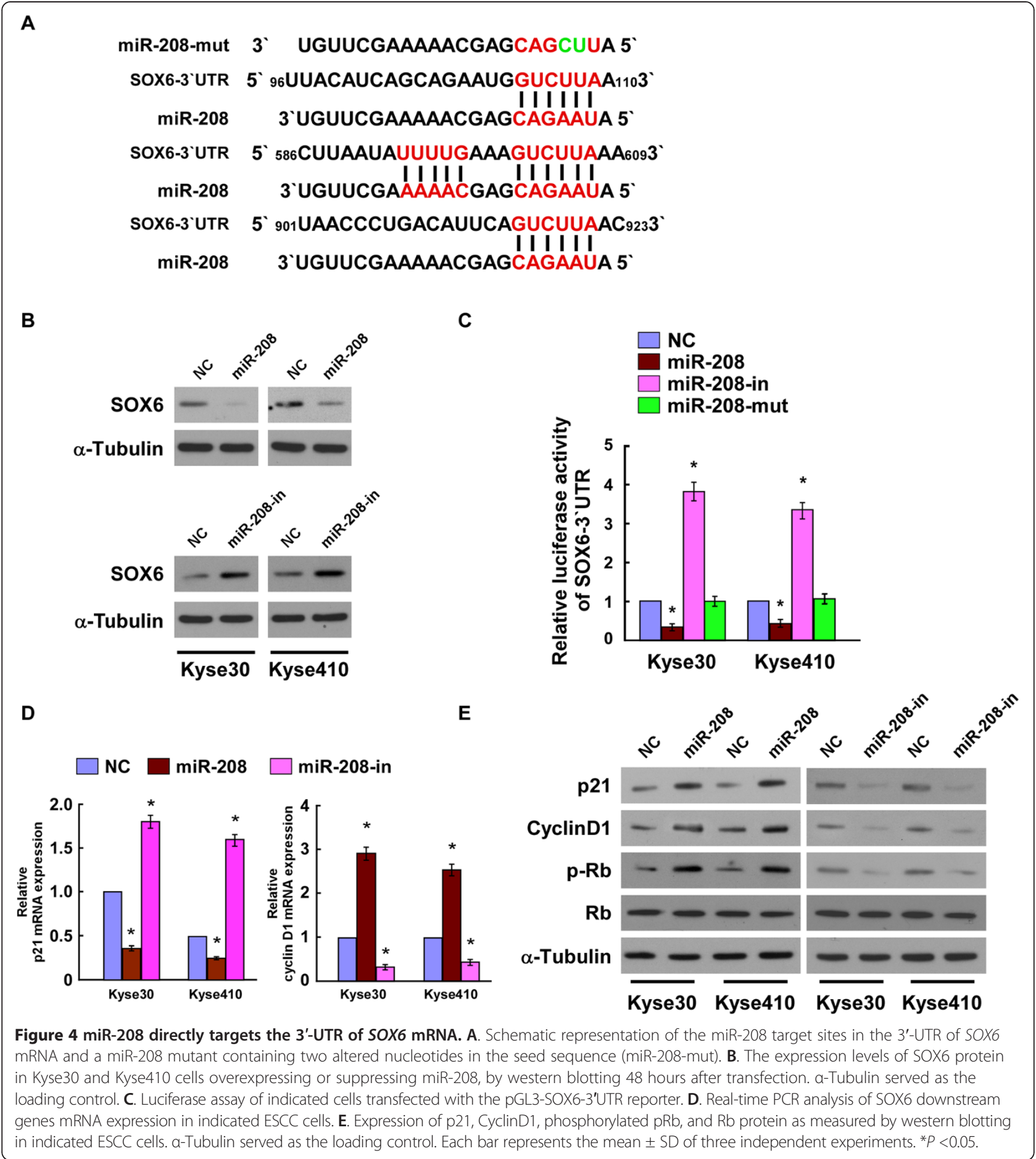

in various cardiovascular diseases [25-27]. Inhibition of miR-208 improved cardiac function and patient survival during heart failure $[27,28]$. However, the expression and function of miR-208 in cancers remain unknown. For the first time, we have demonstrated that miR-208 expression is correlated with ESCC progression and might play an important role during ESCC development. It has also been reported that miR-208 downregulates the Ets1 protooncogene, which is closely involved in the regulation of cell proliferation, differentiation, metastasis, apoptosis, and angiogenesis, by targeting the Ets1 mRNA 3'-UTR [29]. Nevertheless, the expression level of miR-208 in esophageal cancer or other cancers and its clinical relevance, require further study. 


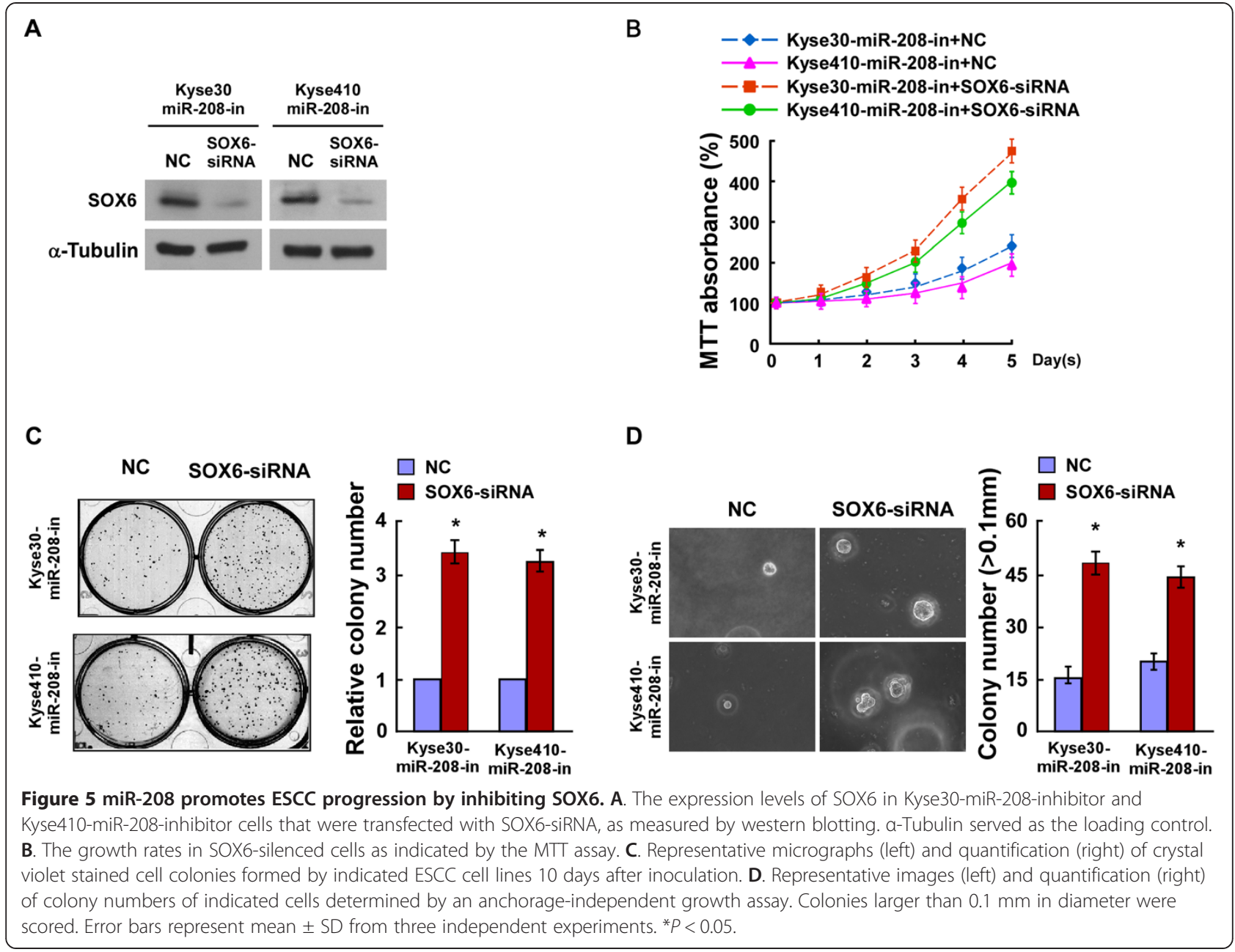

Systematic reporter studies have shown that functional regulation by miRNAs is highly sensitive to base pair mismatches within nucleotides $2-8$ of the miRNA, which have been defined as the seed region [30]. The functional importance of seed region complementarity as the major determinant of miRNA targeting has well established [31], which the microRNAs with mutation in the seed sequences could not genetically match with target genes and fail to inhibit the target genes expression [8,32]. In the current study, we found that miR-208 negatively regulated SOX6 expression by targeting SOX6 3' untranslated region (3'-UTR) in the sequence-specific manner. Consistently, miR-208 with mutated seed sequence failed to show an inhibitory effect on the luciferase activity of SOX6. SOX6 is reported to have a tumor-suppressive function in tumors $[15,16]$. SOX6 suppressed ESCC cells proliferation and cell motility, and inhibited tumor formation. SOX6 also inhibits cell cycle G1/S phage transition by upregulating $\mathrm{p} 53$ and $\mathrm{p} 21^{\mathrm{WAF} 1 / \mathrm{CIP} 1}$, and by downregulating cyclin D1/CDK4, cyclin A and $\beta$-catenin $[14,15]$. In our study, downregulation of SOX6 by miR-208 led to downregulation of $\mathrm{p} 21$, upregulation of cyclin D1, and induced phosphorylation of $\mathrm{Rb}$, resulting in the promotion of cell proliferation and cell cycle progression.

These data suggested that overexpression of miR-208 favored ESCC progression. Most patients with ESCC are diagnosed at an advanced stage with lymph node (LN) metastasis, resulting in a poor prognosis [33]. Therefore, a better understanding of the development of LN metastasis may lead to therapeutic improvements for ESCC patients. SOX6 is closely associated with LN metastasis of ESCC [15]. Whether miR-208 is involved in SOX6-associated LN metastasis needs further study.

In summary, we describe, for the first time, that miR-208 plays an important role in ESCC development and progression. The results reveal that miR-208 is upregulated in ESCC cell lines and tissues. Furthermore, miR-208 overexpression promotes cell proliferation and tumorigenicity in human ESCC cell lines in vitro. Additionally, we identified SOX6 mRNA as a direct and functional target of miR-208. Finally, we revealed that SOX6 suppression is essential for miR-208-induced cell proliferation in ESCC. Based on these results, we propose that miR-208 might be used as a therapeutic agent for ESCC. Further study is required to 
identify the clinical relevance and utility of miR-208 in ESCC diagnosis and therapy.

\section{Competing interests}

All authors declare that they have no competing interests.

\section{Authors' contributions}

$H L, Y G$ and JY participated in the design of study. $H L, D Z, B Z, L L, J O$ and $W C$ performed experimental work. HL, DZ, BZ and SX performed the statistical analysis and helped to draft the manuscript. YG and JY provided administrative support and funded experiments. All authors read and approved the final manuscript.

\section{Acknowledgements}

This study was supported by the Science and Technology Projects Foundation of Guangdong Province (No.2012B031800501) and Natural Science Foundation of Guangdong Province (No.S2012010008827).

\section{Author details}

'Department of Medical Imaging, the First Affiliated Hospital of Sun Yat-sen University, Guangzhou 510080, P.R. China. ${ }^{2}$ Department of Oncology, the First Affiliated Hospital of Sun Yat-sen University, Guangzhou 510080, P.R. China. ${ }^{3}$ Department of Oncology, Nanfang Hosptial, Southern Medical University, Guangzhou 510515, P.R. China. ${ }^{4}$ Department of Thoracic Surgery, the First Affiliated Hospital of Sun Yat-sen University, Guangzhou 510080, P.R. China. ${ }^{5}$ Department of Biochemistry, University of Leicester, Leicester, UK.

\section{Received: 5 January 2014 Accepted: 1 July 2014}

Published: 15 July 2014

\section{References}

1. Parkin DM, Bray F, Ferlay J, Pisani P: Global cancer statistics. 2002. CA Cancer J Clin 2005, 55:74-108.

2. Enzinger PC, Mayer RJ: Esophageal cancer. N Engl J Med 2003, 349:2241-2252.

3. Lee KH, Goan YG, Hsiao M, Lee CH, Jian SH, Lin JT, Chen YL, Lu PJ: MicroRNA-373 (miR-373) post-transcriptionally regulates large tumor suppressor, homolog 2 (LATS2) and stimulates proliferation in human esophageal cancer. Exp Cell Res 2009, 315:2529-2538.

4. Xing D, Tan W, Lin D: Genetic polymorphisms and susceptibility to esophageal cancer among Chinese population (review). Oncol Rep 2003, 10:1615-1623

5. Mizushima T, Nakagawa H, Kamberov YG, Wilder EL, Klein PS, Rustgi AK: Wnt-1 but not epidermal growth factor induces beta-catenin/T-cell factor-dependent transcription in esophageal cancer cells. Cancer Res 2002, 62:277-282.

6. Yang L, Leung AC, Ko JM, Lo PH, Tang JC, Srivastava G, Oshimura M Stanbridge EJ, Daigo Y, Nakamura Y, Tang CM, Lau KW, Law S, Lung ML: Tumor suppressive role of a $2.4 \mathrm{Mb} 9 \mathrm{q} 33-\mathrm{q} 34$ critical region and DEC1 in esophageal squamous cell carcinoma. Oncogene 2005, 24:697-705.

7. Ambros V: The functions of animal microRNAs. Nature 2004, 431:350-355.

8. Bartel DP: MicroRNAs: genomics, biogenesis, mechanism, and function. Cell 2004, 116:281-297.

9. Calin GA, Croce CM: MicroRNA signatures in human cancers. Nat Rev Cancer 2006, 6:857-866.

10. Cimmino A, Calin GA, Fabbri M, lorio MV, Ferracin M, Shimizu M, Wojcik SE, Aqeilan RI, Zupo S, Dono M, Rassenti L, Alder H, Volinia S, Liu CG, Kipps TJ, Negrini M, Croce CM: miR-15 and miR-16 induce apoptosis by targeting BCL2. Proc Natl Acad Sci U S A 2005, 102:13944-13949.

11. Godlewski J, Nowicki MO, Bronisz A, Williams S, Otsuki A, Nuovo G, Raychaudhury A, Newton HB, Chiocca EA, Lawler S: Targeting of the Bmi-1 oncogene/stem cell renewal factor by microRNA-128 inhibits glioma proliferation and self-renewal. Cancer Res 2008, 68:9125-9130.

12. Cho WC: OncomiRs: the discovery and progress of microRNAs in cancers. Mol Cancer 2007, 6:60

13. Hamada-Kanazawa M, Ishikawa K, Ogawa D, Kanai M, Kawai Y, Narahara M, Miyake M: Suppression of Sox6 in P19 cells leads to failure of neuronal differentiation by retinoic acid and induces retinoic acid-dependent apoptosis. FEBS Lett 2004, 577:60-66.

14. Iguchi H, Urashima Y, Inagaki Y, Ikeda Y, Okamura M, Tanaka T, Uchida A, Yamamoto TT, Kodama T, Sakai J: SOX6 suppresses cyclin D1 promoter activity by interacting with beta-catenin and histone deacetylase 1 , and its down-regulation induces pancreatic beta-cell proliferation. $J$ Biol Chem 2007, 282:19052-19061.

15. Qin YR, Tang H, Xie F, Liu H, Zhu Y, Ai J, Chen L, Li Y, Kwong DL, Fu L, Guan XY: Characterization of tumor-suppressive function of SOX6 in human esophageal squamous cell carcinoma. Clin Cancer Res 2010, 17:46-55.

16. Guo X, Yang M, Gu H, Zhao J, Zou L: Decreased expression of SOX6 confers a poor prognosis in hepatocellular carcinoma. Cancer Epidemiol 2013, 37:732-736.

17. Andl CD, Mizushima T, Nakagawa H, Oyama K, Harada H, Chruma K, Herlyn M, Rustgi AK: Epidermal growth factor receptor mediates increased cell proliferation, migration, and aggregation in esophageal keratinocytes in vitro and in vivo. J Biol Chem 2003, 278:1824-1830.

18. Hahn WC, Dessain SK, Brooks MW, King JE, Elenbaas B, Sabatini DM, De Caprio JA Weinberg RA: Enumeration of the simian virus 40 early region elements necessary for human cell transformation. Mol Cell Biol 2002, 22:2111-2123.

19. Li J, Zhang N, Song $L B$, Liao WT, Jiang $L L$, Gong $L Y$, Wu J, Yuan J, Zhang $H Z$, Zeng MS, Li M: Astrocyte elevated gene-1 is a novel prognostic marker for breast cancer progression and overall patient survival. Clin Cancer Res 2008, 14:3319-3326.

20. Esquela-Kerscher A, Slack FJ: Oncomirs - microRNAs with a role in cancer. Nat Rev Cancer 2006, 6:259-269.

21. Rabinowits G, Gercel-Taylor C, Day JM, Taylor DD, Kloecker GH: Exosomal microRNA: a diagnostic marker for lung cancer. Clin Lung Cancer 2009, 10:42-46.

22. Stahlhut Espinosa CE, Slack FJ: The role of microRNAs in cancer. Yale J Biol Med 2006, 79:131-140

23. Blenkiron C, Goldstein LD, Thorne NP, Spiteri I, Chin SF, Dunning MJ, Barbosa-Morais NL, Teschendorff AE, Green AR, Ellis IO, Tavaré S, Caldas C, Miska EA: MicroRNA expression profiling of human breast cancer identifies new markers of tumor subtype. Genome Biol 2007, 8:R214.

24. Mitchell PS, Parkin RK, Kroh EM, Fritz BR, Wyman SK, Pogosova-Agadjanyan EL, Peterson A, Noteboom J, O'Briant KC, Allen A, O'Briant KC, Allen A, Lin DW, Urban N, Drescher CW, Knudsen BS, Stirewalt DL, Gentleman R, Vessella RL, Nelson PS, Martin DB, Tewari M: Circulating microRNAs as stable blood-based markers for cancer detection. Proc Natl Acad Sci U S A 2008, 105:10513-10518.

25. Cai B, Pan Z, Lu Y: The roles of microRNAs in heart diseases: a novel important regulator. Curr Med Chem 2010, 17:407-411.

26. Han M, Toli J, Abdellatif M: MicroRNAs in the cardiovascular system. Curr Opin Cardiol 2011, 26:181-189.

27. Malizia AP, Wang DZ: MicroRNAs in cardiomyocyte development. Wiley Interdiscip Rev Syst Biol Med 2011, 3:183-190.

28. Montgomery RL, Hullinger TG, Semus HM, Dickinson BA, Seto AG, Lynch JM, Stack C, Latimer PA, Olson EN, van Rooij E: Therapeutic inhibition of miR-208a improves cardiac function and survival during heart failure. Circulation 2011, 124:1537-1547.

29. Itoh T, Takeda S, Akao Y: MicroRNA-208 modulates BMP-2-stimulated mouse preosteoblast differentiation by directly targeting $\mathrm{V}$-ets erythroblastosis virus E26 oncogene homolog 1. J Biol Chem 2010, 285:27745-27752.

30. Doench JG, Sharp PA: Specificity of microRNA target selection in translational repression. Genes Dev 2004, 18:504-511.

31. Krek A, Grun D, Poy MN, Wolf R, Rosenberg L, Epstein EJ, MacMenamin P da Piedade I, Gunsalus KC, Stoffel M, Rajewsky N: Combinatorial microRNA target predictions. Nat Genet 2005, 37:495-500.

32. Shukla GC, Singh J, Barik S: MicroRNAs: processing, maturation, target recognition and regulatory functions. Mol Cell Pharmacol 2011, 3:83-92.

33. Rice TW, Zuccaro G Jr, Adelstein DJ, Rybicki LA, Blackstone EH, Goldblum JR: Esophageal carcinoma: depth of tumor invasion is predictive of regional lymph node status. Ann Thorac Surg 1998, 65:787-792.

doi:10.1186/1479-5876-12-196

Cite this article as: Li et al: Mir-208 promotes cell proliferation by repressing SOX6 expression in human esophageal squamous cell carcinoma. Journal of Translational Medicine 2014 12:196 